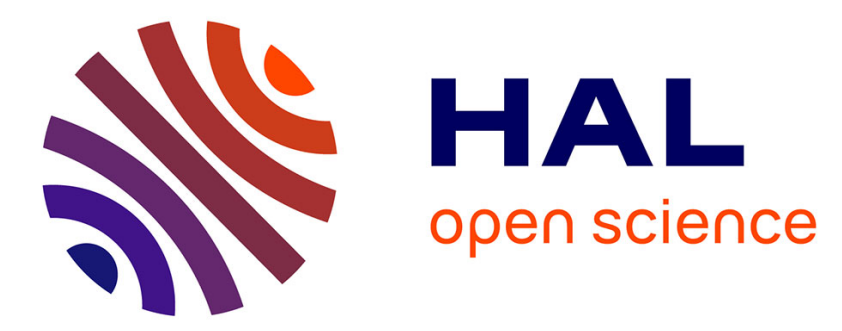

\title{
Factory of the Future: The industrial transition through the prism of co-evolution
}

Flor de Asis Marti Nieto, Virginie Goepp-Thiebaud, Emmanuel Caillaud

\section{To cite this version:}

Flor de Asis Marti Nieto, Virginie Goepp-Thiebaud, Emmanuel Caillaud. Factory of the Future: The industrial transition through the prism of co-evolution. IEEE International Conference on Systems, Man and Cybernetics (SMC 2019), IEEE, Oct 2019, Bari, Italy. pp.3337-3342, 10.1109/SMC.2019.8914506 . hal-03078888

\section{HAL Id: hal-03078888 \\ https://hal.science/hal-03078888}

Submitted on 16 Dec 2020

HAL is a multi-disciplinary open access archive for the deposit and dissemination of scientific research documents, whether they are published or not. The documents may come from teaching and research institutions in France or abroad, or from public or private research centers.
L'archive ouverte pluridisciplinaire HAL, est destinée au dépôt et à la diffusion de documents scientifiques de niveau recherche, publiés ou non, émanant des établissements d'enseignement et de recherche français ou étrangers, des laboratoires publics ou privés. 


\title{
Factory of the Future: The industrial transition through the prism of co-evolution*
}

\author{
Flor de A. Marti Nieto, Virginie Goepp, Emmanuel Caillaud
}

\begin{abstract}
The shift towards the future of manufacturing is a main stake for companies to remain competitive. This paper proposes to manage this shift in a global manner through an enhanced co-evolution model. It takes into account the main enterprise domains that have to 'co-evolve': product, manufacturing and information system. The model also integrates the role of the strategy and of the human workforce which are crucial in the Factory of the Future context. We identify the modeling constructs required to support an efficient co-evolution management.
\end{abstract}

\section{INTRODUCTION}

In order to fully realize their potential, modern organizations have stepped up their efforts to bring better practices and advanced performance for industrial evolution associated to the concepts of Factory of the Future (FoF) [1], Smart Factory [2] or even Industry 4.0 [3]. A big issue for organizations is to manage this transition from a given situation towards a target evolved scenario. The promise that parallels this transition is set against a wide range of technological, organizational and societal challenges [4].

In the last decades, research agendas have been devoted to develop new methods, techniques and tools to master the transformation of industries. These works have generally adopted a focus on techno-centred issues, and less attention has been paid to approaches allowing a global engineering point of view.

Factory of the Future as the counterpart of Industry 4.0smart factory aims at improving the overall performance of the factory through developing communication within the company. In order to manage such a transformation, the role of human workers [5] and the evolution of the Information System (IS) [6] are major concerns to be tackled.

The goal we are striving is to conceive an approach that helps to ensure the transition from a specific situation to a situation that reaches the context of FoF. In this line of action, the model developed by Tolio, et al. [7] is promising since it considers a co-evolution problem including product, process and production system. As stated by the authors, the management of co-evolution will allow manufacturing companies 'to operate at a point that preserves the feasibility

*Research supported by CONACYT

Flor De A. Marti N. is with the ICube Laboratory - INSA 24 bld de la Victoire 67084 Strasbourg Cedex France (phone: +33783403106; e-mail: flor-de-asis.marti-nieto@etu.unistra.fr).

Virginie Goepp is with ICube Laboratory - INSA 24 bld de la Victoire 67084 Strasbourg Cedex France (e-mail: virginie.goepp@insastrasbourg.fr).

Emmanuel Caillaud is with the ICube Laboratory - Unistra 3 rue de l’Université 67000 Strasbourg France (e-mail: caillaud@unistra.fr). and profitability of the performed processes in spite of the dynamic context' alike FoF's.

Therefore, in this study we are interested in co-evolution as a mean to successfully exploit these interactions to orchestrate the desired transformation. However, the model proposed by Tolio et al. does not aim at enabling the management of co-evolution. Indeed, the scope of proposed model provide a coarse definition of the entities considered to co-evolve. Therefore, it limits the range of decisions and their interdependencies enabling to ensure a successful transformation. Moreover, the model lacks the explicit representation of strategic decisions on which these management choices rely on (i.e. to match the firm's business with the dynamics of the environment) $[8,9]$.

Therefore, in this paper we propose an enhanced coevolution model built on the co-evolution model proposed by Tolio, et al. [7]. We analyze, identify and develop the missing elements required to conceive a co-evolution modelling approach enabling to design a path to achieve a desired future industrial scenario. The novelty of our co-evolution model regards the following statements:

- The operational application of our co-evolution model through the use of enterprise modelling techniques.

- The consideration of strategic dimension; the integration of the IS domain to address required choices concerning Information Technologies (IT), as well as the impact on the role of human workforce.

In fact, our co-evolution model strives to take a step further in terms of strategic alignment to effectively cope with the complexity of manufacturing businesses towards higher competitiveness as required for FoF.

This paper is structured as follows. In section 2 we detail the original model. We also discuss its strengths and limitations to deal with the co-evolution management as required for the transition to the Factory of the Future and how the model can be adapted to this objective. In section 3, we first modify and complete the original model by exploiting the Strategic Alignment Model (SAM) [10] and the related work of Avila, et al. [11] about the E-SAM. Then, we detail the content of this model with the corresponding enterprise modeling constructs stemming from ISO 19440 [12]. Conclusions and perspectives are drawn in section 4. 


\section{Initial Co-EVolution Model Analysis}

\section{A. Co-evolution Model Overview}

The work of Tolio, et al. [7] is based on the "co-evolution paradigm". This paradigm is defined as: "the repeated configuration of products, process and production system over time". To manage co-evolution, they proposed a model that allows to delimit a space where co-evolution management approaches, tools and problems can be mapped.

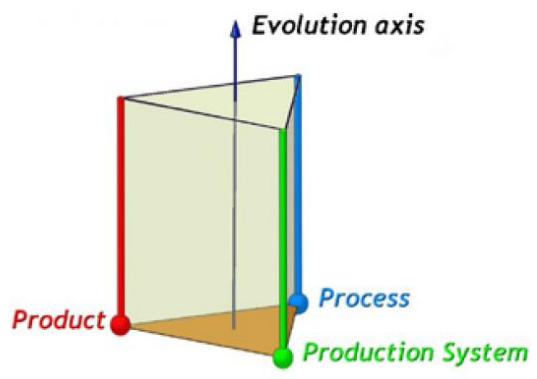

Figure 1. Graphical representation of the co-evolution model (Tolio et al., 2010)

The model takes a geometrical shape represented by a triangular prism (See Figure 1). The edges of the prism stand for the three "configuration entities" (P3S): products, process and production system. The prism includes a vertical axis to represent the evolution axis. At any level of the evolution axis, the triangular cross-section represents the integration space among the three entities.

\section{B. Co-Evolution Management Process}

The Co-Evolution Management process of the original co-evolution model is considered as a configuration activity of the product, process and production system entities. Authors propose two metrics to evaluate a given configuration approach enabling to choose the one fitting the best to a specific configuration context. These metrics are the integration level and the evolution level. The integration level aims at analyzing the way a given approach enables to work out a configuration solution. It is mapped within the integration space of the model.

The evolution level is the capability of a configuration approach to take into account potential evolutions of the entities. It is mapped at the vertical axis through check points in order to evaluate the configuration approach at a given time period.

\section{General Analysis and Conclusions concerning the Co- evolution Model}

Tolio, et al. [7] consider co-evolution as the repeated configuration of the product, process and production System entities. The authors show that this co-evolution is crucial in environments subject to continuous changes like the context of $\mathrm{FoF}$, in which we are interested. The related management consists in choosing the configuration approach fitting the best to a given situation. In other words, the co-evolution model they propose is used to map and analyze existing configuration approaches. This provides a global overview of the existing approaches but does not provide an effective support to manage the potential interactions between the entities to be configured.

Therefore, in our view, the co-evolution model can be exploited to manage these interactions. It can help to understand and manage the multi-level interactions that explain competition and change across the organization, considering also their interdependencies like found in biological evolution $[13,14]$. However, if the co-evolution is used in this sense, entities subject to configuration have to be further detailed especially the characteristics required to make design decisions. Correlations among them and with respect to higher decision levels of the organization must be taken into account. Furthermore, the strategic dimension is has to be more explicitly depicted in the model.

Therefore, in order to guide the co-evolution towards FoF's, we aim to complete the proposed co-evolution model with the following aspects that we consider necessary to address: 1) the explicit consideration of the role of the Information System (IS) within the model, not only from its the technological function (i.e. IT functionality) but from its key role at the center of the major managerial functions adding value to the firm's processes and 2) the consideration of strategic dimension since it involves the pattern of decisions that leads the activities of the firm into a specific direction [15].

By developing these objectives, we argue that a more powerful co-evolution model can be built and further applied as an effective management tool towards a FoF environment. The next section will explain the resulting restructuring of the model involving new domains' decision areas for both internal and external levels of analysis.

Particular attention should be paid to the underlying choices regarding the role of human. Choices of the human dimension namely their competencies and skills will be included in our co-evolution model. In the further discussion will also argue how our contribution can potentially cover the dynamics of choices concerning the development of human beings in response to the objectives of the changing organization.

\section{PRoposal of AN ENHANCED CO-EVOLUTION MODEL}

In this section, we present in detail the completed coevolution model taking the model presented in [7] as a starting point. To succeed in, we rely on:

- A detailed analysis of the P3S entities of the already defined model to set up the domains of our enhanced co-evolution model.

- The Strategic Alignment Model (SAM) of Henderson and Venkatraman [16] enabling to integrate the strategic dimension into our model.

- Enterprise Modeling (EM) techniques which provide means to describe process oriented systems and decompose them into manageable parts [17]. We exploit the ISO standards for EM: ISO 19440 [12] to define the modeling constructs required to represent the domains of our model. 


\section{A. Definition of the new domains of the co-evolution model}

Redefinition of the P3S entities into domains of the enhanced co-evolution model: Our first concern aims at complementing the co-evolution view as depicted in the model which considers three basic entities: the product, the process and the production system. According to the definition of the entities, it is assumed that interactions only result from the transforming process that relates the input and the output of a system. As such, the model reduces the scope of co-evolution to the physical process through which an output, namely a product is obtained by means of a performed production system.

So, we consider this proposal as a preliminary effort that provides direction for addressing co-evolution to a broader context that complies with the range of activities and decisions. In this context, we suggest to redefine the proposed entities into domains. Into each domain we can thus specify the set of decisions that should mutually co-evolve for enabling 'as-is' reengineering.

Moreover, by defining functional domains like product design, product manufacturing etc., their specific composition can be captured for users requests and possible interrelations can be clearly focused. From the Enterprise Modelling viewpoint this is a modular way allowing to deal with the overall system complexity [18].

Therefore, two main domains are derived based on the entities of the original model:

- The Product Design domain is composed of the product entity. Nevertheless, we propose to expand the initial concept to consider the processes of product development like appropriate design methods which can affect manufacturing costs or productivity. Indeed, product design, both as an outcome and a process is relevant for organizational success [19].

- The Manufacturing domain bundles the process and the production system into the same domain. This is because both are closely related since they rely on each other to carry out the transformation for a product. The concepts emphasize this aspect as they define the process as the logical procedures executed by the production system and this latter as a set of resources and policies that in turn allow the execution of the processes.

Definition of the Information System (IS) domain of the enhanced co-evolution model: According to our objective we add the IS domain to tackle the decisions regarding the setup of the IS matching the needs of the enterprise. The IS has a key role on organization to support the execution of operational, managerial and executive-level processes. Furthermore, IS academics broadly agree that IS has to be considered as an entire functional domain on its own, being at the core of business process and Information Technology (IT) evolutions. As result, IS needs to be aligned with the business activity and new technologies in order to create value for the organization and effectively support innovation [20].

\section{Integration of the Strategic Dimension}

Concerning the strategic dimension, we exploit the Strategic Alignment Model (SAM) proposed in [10]. This is one of the first frameworks that considers simultaneously the strategic and implementation levels of analysis. The authors detail these levels as follows:

- The external level, also called the 'strategic level' deals with the arena in which the firm competes, their attributes that differentiate it from its competitors, the decisions regarding product-market offering as well as "make-versus-buy" decisions, including partnerships and alliances.

- The internal level, also called the 'structural level' concerns the implementation choices related to the logic of the administrative structure and the specific rationale for the design and redesign of critical business process, and the resources to operate and manage it.

As the distinction made by the SAM, we split each domain of our co-evolution model into two levels: the internal level and the external one. The definition of the domains has to include the content of each domain to support co-evolution management as defined in section 2.C. This is done in section 3.C exploiting the E-SAM proposed by Avila, et al. [11] which add two domains to the classical SAM: product design and production. We use these domains in our model.

\section{B. Internal Structure of Domains}

The general sub-domain structure of the E-SAM is the same as the one of the SAM with three components per subdomain: (1) The scope (or perimeter), competencies and governance in the external level; (2) The infrastructure, skills and process in the internal level. We use the same component structure for the six sub-domains of our co-evolution model because the decisions specified are common to the concerns we aim to tackle for the internal and external level of the coevolution approach.

As a result, the Erreur ! Source du renvoi introuvable. shows the general structure of the proposed co-evolution model. The next section details the content of each component.

\section{Modeling the Components of the Co-evolution Model}

As the modeling purposes differ between the internal and the external level, the way to model them also differs.

Modeling of the Strategical level of the Co-evolution: Since the external level is related to the strategies, their modeling must enable to represent the strategic behavior of companies in the form of decisions or activities that are in harmony with the enterprise activities performed. This aspect is already tackled by the set of decisions of the domain's components within the E-SAM. So, for this level we exploit them as presented in Table 1. 


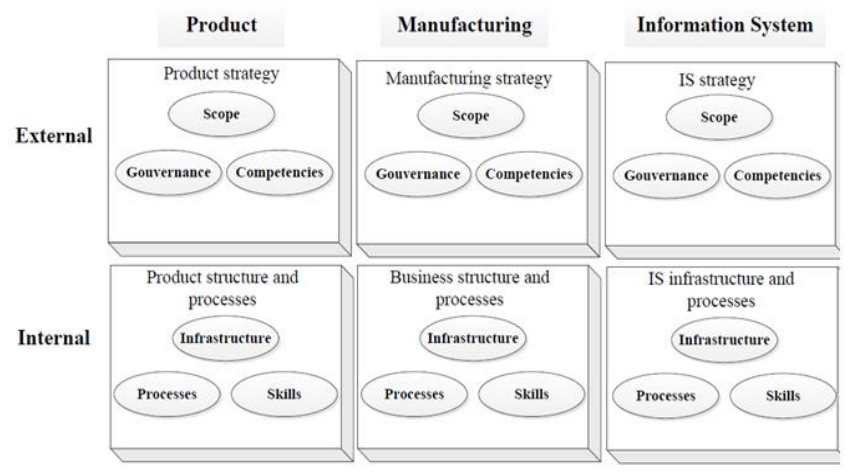

Figure 1. The detailed representation of the completed Co-evolution model

TABLE 1. DECISION-BASED MODELING OF STRATEGIC LEVEL OF THE COEVOLUTION MODEL

\begin{tabular}{|c|c|c|c|}
\hline & \multicolumn{3}{|c|}{ External Structure of Domains in the Enhanced Co-evolution Model } \\
\hline & Product & Manufacturing & IS \\
\hline $\begin{array}{l}\text { ¿ } \\
\text { ठ } \\
\tilde{n}\end{array}$ & $\begin{array}{l}\text { Technological } \\
\text { integration: New } \\
\text { Design } \\
\text { Technologies } \\
\text { Distinctive } \\
\text { Product's features: } \\
\text { Structure, } \\
\text { Functionality, } \\
\text { Performance, } \\
\text { Quality }\end{array}$ & $\begin{array}{l}\text { Production } \\
\text { Technologies } \\
\text { Types of technologies } \\
\text { Degree of } \\
\text { systematization } \\
\text { Degree of automation } \\
\text { Degree of } \\
\text { interconnection } \\
\text { Product's types } \\
\text { Product variety and } \\
\text { scope } \\
\text { Time to market of new } \\
\text { products } \\
\text { Final product } \\
\text { complexity }\end{array}$ & $\begin{array}{l}\text { Current or new } \\
\text { ITs } \\
\text { IS governance } \\
\text { IS strategic } \\
\text { alliances and } \\
\text { partnerships }\end{array}$ \\
\hline 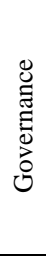 & $\begin{array}{l}\text { Partnership for } \\
\text { Design: Alliances, } \\
\text { Partnership, } \\
\text { Outsourcing } \\
\text { Design Policies: } \\
\text { Competitiveness } \\
\text { /Profitability, } \\
\text { Product Life cycle }\end{array}$ & $\begin{array}{l}\text { Vertical Integration } \\
\text { Make -or-buy } \\
\text { decisions } \\
\text { Alliances } \\
\text { Upstream Integration }\end{array}$ & $\begin{array}{l}\text { Partnership for } \\
\text { IT } \\
\text { Alliances } \\
\text { Joint venture } \\
\text { with vendors } \\
\text { Join research } \\
\text { and } \\
\text { development }\end{array}$ \\
\hline 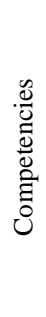 & $\begin{array}{l}\text { Design } \\
\text { Competencies: } \\
\text { Innovative Design, } \\
\text { Design of } \\
\text { customized } \\
\text { products, Design of } \\
\text { modular products, } \\
\text { Design of serial } \\
\text { products }\end{array}$ & $\begin{array}{l}\text { Production Capacity } \\
\text { Size, Location of } \\
\text { Facilities } \\
\text { Capacity } \\
\text { Level of reliability } \\
\text { Level of flexibility }\end{array}$ & $\begin{array}{l}\text { Systemic } \\
\text { Competencies } \\
\text { System } \\
\text { reliability } \\
\text { Cost- } \\
\text { performance } \\
\text { levels } \\
\text { Inter- } \\
\text { connectivity } \\
\text { Flexibility }\end{array}$ \\
\hline
\end{tabular}

Modeling of the Structural level of the Co-evolution: Coevolution management requires structured modeling of the internal level. Therefore, we propose to exploit modeling constructs of EM defined in ISO 19440 [12] by mapping them with the internal components of the co-evolution model, as they do not fit naturally into each other. We take into account guidance on a previous mapping presented in [21] between the components of the SAM and the constructs of ISO 19440 [12]. The results of our mapping are detailed in Table 2
Following the results of the mapping, the first four constructs of the function view correspond to the processes of the product design, manufacturing and IS domain. These four constructs: Domain, Business Process, Enterprise Activity and Event, represent the functional aspects of the enterprise, meaning their processes and activities.

The next four constructs of the information view involve information-related entities used and obtained during enterprise operations. The Enterprise Object and Object view constructs refer to the inputs and outputs of enterprise activities or enterprise object, respectively. As such, these constructs are mapped to the processes of our domains since they have to be defined for the process operation. They are also mapped to the architecture of the IS domain since they refer to the definition of the data architecture. Regarding the constructs of Product and Order, both are specializations of the Enterprise object construct. Concerning the Product, this construct is represented as the output of an enterprise's process. Products have to be described within the process component of the manufacturing and product design domain where it is mapped. The Order construct represents the 'information for planning and control of a business process in an enterprise'. It may be also the end-result of a business process used to describe a further activity. As a result, we map it to the process component of the product design and manufacturing for which orders have to be described.

In the resource view, we consider the Resource construct and its specialization. The Functional entity construct describes required capabilities that any enterprise activity needs in order to take place. They include the equipment, facilities, people and organizational groupings, as well as equipment for data processing. As such, both resource and functional entity constructs are mapped to the infrastructure of manufacturing and IS. Operational capabilities or skills provided by a resource or required by the enterprise activity are also described here and are mapped to the skills component of each domain. Regarding the Capability construct, it describes attributes related to the identified resources like constraints that have to do with processing such as tooling dimensions, data processing or time restrictions. As a result, capability construct match with the architecture of manufacturing and IS but it is not linked to the product design domain.

The organizational view represents the organization, organizational relationships and decision-making responsibilities in the enterprise operation. The construct of Organizational unit refers to the roles and responsibilities to perform human tasks within a given hierarchical structure. Thus, we map this construct to the skills component and the design structure of the product design domain. Similarly, the construct of Organizational cell is mapped to the design structure component since it refers to the hierarchical structure of an enterprise like divisions and departments. At last, the Decision Centre construct deals with decision system modeling. In our view, this construct is not linked to any modeling concern of the co-evolution model's components.

\section{Considerations on human role from the resource view}

One of the fundamental aspects to consider concerns the implications of organization' changes on human beings' skills and experience. The importance of that matter has 
triggered the setting of an agenda in the European Union, which is known as the Lisbon Strategy, to achieve the most competitive and dynamic knowledge-based economy in the world [22].

TABLE 2. MAPPING MADE BETWEEN THE INTERNAL COMPONENTS OF THE CO-EVOLUTION MODEL AND THE MODELING LANGUAGE CONSTRUCTS FROM ISO $19440[12]$

\begin{tabular}{|c|c|c|c|c|c|c|c|c|c|c|}
\hline & \multirow[b]{4}{*}{$\begin{array}{c}\text { Modelling Constructs } \\
\text { ISO19440 } \\
\end{array}$} & \multicolumn{9}{|c|}{ Co-evolution Model Components at Internal level } \\
\hline & & \multicolumn{3}{|c|}{ Product } & \multicolumn{3}{|c|}{ Manufacturing } & \multicolumn{3}{|c|}{ IS } \\
\hline & & \multirow{2}{*}{ 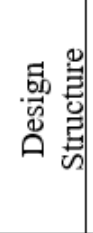 } & \multirow{2}{*}{ 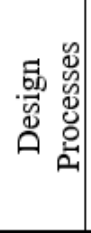 } & \multirow[t]{2}{*}{$\frac{n}{\sqrt[3]{2}}$} & \multirow{2}{*}{$\begin{array}{l}\text { 异 } \\
\text { 总 } \\
\text { 㥕 } \\
\text { 岁 }\end{array}$} & \multirow{2}{*}{ 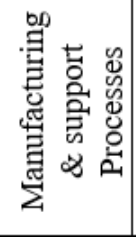 } & \multirow[t]{2}{*}{ 当 } & \multirow{2}{*}{ 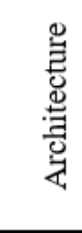 } & \multirow{2}{*}{ 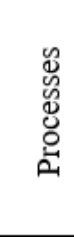 } & \multirow[t]{2}{*}{ 音 } \\
\hline $\begin{array}{c}\text { Modelling views } \\
\text { ISO19439 } \\
\end{array}$ & & & & & & & & & & \\
\hline \multirow[t]{4}{*}{ Function View } & Domain & & $\mathrm{x}$ & & & $\mathrm{x}$ & & & $\mathrm{x}$ & \\
\hline & Business Processes & & $\mathrm{x}$ & & & $\mathrm{x}$ & & & $\mathrm{x}$ & \\
\hline & Enterprise Activity & & $\mathrm{x}$ & & & $\mathrm{x}$ & & & $\mathrm{x}$ & \\
\hline & Event & & $\mathrm{x}$ & & & $\mathrm{x}$ & & & $\mathrm{x}$ & \\
\hline \multirow{4}{*}{$\begin{array}{l}\text { Information } \\
\text { View }\end{array}$} & Enterprise Object & & $\mathrm{x}$ & & & $\mathrm{x}$ & & $\mathrm{x}$ & & \\
\hline & Object view & & $\mathrm{x}$ & & & $\mathrm{x}$ & & $\mathrm{x}$ & & \\
\hline & Product & & $\mathrm{x}$ & & & $\mathrm{x}$ & & & & \\
\hline & Order & & $\mathrm{x}$ & & & $\mathrm{x}$ & & & & \\
\hline \multirow[t]{3}{*}{ Resource View } & Resource & & & $\mathrm{x}$ & $\mathrm{x}$ & & $\mathrm{x}$ & $\mathrm{x}$ & & $\mathrm{x}$ \\
\hline & Functional Entity & & & $\mathrm{x}$ & $\mathrm{x}$ & & $\mathrm{x}$ & $\mathrm{x}$ & & $\mathrm{x}$ \\
\hline & Capability & & & & $\mathrm{x}$ & & & $\mathrm{x}$ & & \\
\hline \multirow{3}{*}{$\begin{array}{l}\text { Organisational } \\
\text { View }\end{array}$} & Organisational Unit & $\mathrm{x}$ & & $\mathrm{x}$ & $\mathrm{x}$ & & $\mathrm{x}$ & & & $\mathrm{x}$ \\
\hline & Organisational Cell & $\mathrm{x}$ & & & & & & & & \\
\hline & Decision Centre & & & & & & & & & \\
\hline
\end{tabular}

In our contribution, we consider human role by exploiting the decision set of 'competencies' and 'skills' as defined in the E-SAM. As a result, we can address human's role by modelling it as a resource within high and low levels of the organization. For this purpose, we follow the modelling standard ISO 19440 [12] through the predefined 'resource view'. The resource view allows to represent the roles and responsibilities of human resources. Thus, based on the established standard, we can integrate in the co-evolution model decisions of the profile required to perform a task, including the required capacities that must be fulfilled as skills and functions. In this way, we are able to handle the dynamics of the human's role in response to strategic and structural rearrangements. Moreover, we can consider the necessary alignment of the perceived skills' gap in relation to the desired state that the organization seeks to meet.

\section{CONCLUSIONS AND PERSPECTIVES}

Organizations are struggling to keep the pace with evolutions whereby they have to make co-evolve their subsystems. That's why co-evolution becomes relevant in order to enact successful engineering changes while maintaining the coherence along the whole business structure. Relying on the work of Tolio, et al. [7], in this paper we have consolidated a co-evolution model with the aim to help firms to foster adaptation looking towards nextgeneration factories.

Taking the prior model as starting point, we have pointed out that co-evolution must take an integrated approach of the key interdependencies that can lead firms to change and adapt themselves to future contexts. As a result, our first contribution is to build up three key domains: product design, manufacturing and IS as the ones interacting within the prism of coevolution.

According to [7], from a co-evolution stance, successful transition results from the strategic and operational management of engineering changes that propagate to the different levels of the organization. Consistent with this notion, we have defined two levels of analysis for each domain: the internal and external level. The interdependencies between each other, specifically the way they can be modelled and managed over the time are the main motivation behind this work. As a result, we have taken into account the strategic links that were missing. Furthermore, the role of human workforce can be addressed through the domain's content related to the competences and skills of human resources. The definition of the two-level structure is made in analogy with the SAM [10] while the content's detail of the resulting 6 sub-domains is based on the E-SAM [11].

Taking a step further in completing the co-evolution model, we have exploited the modeling constructs for enterprise models of ISO 19440 [12]. Hence, we have mapped the standardized constructs to the content of the internal sub-domains. By making this we provide a common modelling representation that opens up further research on extending co-evolution for architectural contexts of an organization.

More importantly, the generic constructs related to the view Resource and the Organizational view allow us to describe and create instances of the profile skills that human beings deliver. As such, the impact of human factors can be 
considered in the co-evolution from the current to the desired state. Furthermore, a further development could be pursued by refining constructs in the Resource view to include specific management concerns related for example to the planning of the personnel or the assignment of the workplaces.

To effectively support co-evolution management, we will further choose relevant modeling languages to formally represent the processes of the internal sub-domains. For instance, BPMN (Business Process Modeling Notation) [23] and UML (Unified Modeling Language) [24] are both widely recognized standards with support from many tools. The first one focuses on business process modeling including visual description like workflows that allows to analyze the business process in detail. As such, BPMN can efficiently drive the translation from the conceptual design to their implementation. The second modeling language, UML, supports software applications and software architecture modeling.

The precedent efforts represent the first stage of our work. In further steps we will consider the managerial implications that can arise from the instantiation of the co-evolution model related to a current and future organization state (i.e. "As-Is" and "To-Be" business process). To do so, we aim to identify potential relationships across the domain's models, meaning domain-to-domain interactions as well as those between their internal components. Further, we will characterize these interactions and build "co-evolution sequences" in terms of the attributes of the specific relationship (i.e. the direction from one specific domain to another) and their degree of impact (i.e. poor, necessary, insufficient). Empirical evidence will be necessary to validate the completed co-evolution approach.

The time dimension is an integrative part of the coevolution model since changes are propagated at different time intervals with respect to each of the domains. Conceptually, time has been represented in the original model through a vertical axis plotted at the center of the triangular prism of the P3S entities (see Figure 1). We have kept this representation in order to depict how the new defined domains of the firm co-evolve over time. From a macroscopic point of view, this evolution axis should also take place within a prism having our redefined domains at the edges.

\section{REFERENCES}

[1] I. Welber, "Factory of the future," IEEE Control Systems Magazine, vol. 7, no. 2, pp. 20-22, 1987.

[2] D. Lucke, C. Constantinescu, and E. Westkamper, "Smart factory - A step towards the next generation of manufacturing," in Manufacturing Systems and Technologies for the New Frontier: 41 st CIRP Conference on Manufacturing Systems, May 26-28. Tokyo, Japan, 2008: Springer, pp. 115-118.

[3] R. Drath and A. Horch, "Industrie 4.0: Hit or Hype? [Industry Forum]," IEEE Industrial Electronics Magazine, vol. 8, no. 2, pp. 5658, 2014.

[4] K. D. Thoben, M. Busse, B. Denkena, and J. Gausemeier, "Editorial: System-integrated Intelligence - New Challenges for Product and Production Engineering in the Context of Industry 4.0," in 2nd International Conference on System-Integrated Intelligence: Challenges for Product and Production Engineering, Jul 02-04, Bremen,Germany, 2014, vol. 15: Elsevier Science, in Procedia Technology, pp. 1-4.
[5] A. Moeuf, R. Pellerin, S. Lamouri, S. Tamayo-Giraldo, and R. Barbaray, "The industrial management of SMEs in the era of Industry 4.0," International Journal of Production Research, vol. 56, no. 3, pp. $1118-1136,2018$

[6] M. Haddara and A. Elragal, "The Readiness of ERP Systems for the Factory of the Future," in Conference on Enterprise Information Systems/International Conference on Project Management/Conference on Health and Social Care Information Systems and Technologies, 2015, Oct 7-9. Vilamoura, Portugal 2015, vol. 64: Elsevier Science in Procedia Computer Science, pp. 721-728.

[7] T. Tolio et al., "SPECIES-Co-evolution of products, processes and production systems," Cirp Annals-Manufacturing Technology, vol. 59, no. 2, pp. 672-693, 2010.

[8] J. Karimi, "Strategic Planning for Information Systems: Requirements and Information Engineering Methods," Journal of Management Information Systems, vol. 4, no. 4, pp. 5-24, 1988.

[9] V. M. Papadakis, S. Lioukas, and D. Chambers, "Strategic DecisionMaking Processes: The Role of Management and Context," Strategic Management Journal, vol. 19, no. 2, pp. 115-147 1998.

[10] J. Henderson and N. Venkatraman, Strategic Alignment: Leveraging Information Technology for Transforming Organizations. 1993, pp. 416.

[11] O. Avila, V. Goepp, and F. Kiefer, "Towards and extended alignment model for a complete alignment of manufacturing information systems," in International Conference on Enterprise Information Systems (ICEIS'08 ${ }^{\circ}$, Barcelona, Spain, June 2008, pp. 12-16.

[12] ISO 19440, "Enterprise Integration-Constructs for enterprise modelling," in International Standards Organization, ed. Geneva, Switzerland, 2007.

[13] G. Abatecola, F. Belussi, D. Breslin, and I. Filatotchev, "Darwinism, organizational evolution and survival: key challenges for future research," Journal of Management \& Governance, vol. 20, no. 1, pp. 1-17, March 012016

[14] A. C. Penn and A. Liu, "Coevolutionary and Symbiotic Relationships in Design, Manufacturing and Enterprise," Procedia CIRP, vol. 70, pp. 247-252, 2018.

[15] R. H. Hayes and S. C. Wheelwright, Restoring our Competitive Edge: Competing Through Manufacturing, J. Wiley, ed., New York, 1984.

[16] J. C. Henderson and H. Venkatraman, "Strategic alignment: Leveraging information technology for transforming organizations," IBM Systems Journal, vol. 32, no. 1, pp. 472-484, 1993.

[17] M. Zelm, F. B. Vernadat, and K. Kosanke, "The CIMOSA business modelling process," Computers in Industry, vol. 27, no. 2, pp. 123$142,1995$.

[18] Berio Giuseppe and F. B. Vernadat, "Enterprise Modelling with CIMOSA: Functional and organizational aspects," Production Planning and Control vol. 12, no. 2, pp. 128-136, 2001.

[19] S. Chen, The Design Imperative, 1 st ed. (The Art and Science of Design Management ). Palgrave Macmillan, 2018, p. 233.

[20] M. J. Ferreira, F. Moreira, and I. Seruca, "Digital Organization - a new challenge in the Information Systems Curriculum," in INTED2017 Proceedings Valencia, Spain, 2017, in 11th International Technology, Education and Development Conference, pp. 2437-2447.

[21] V. Goepp and M. Petit, "A Systematic Evaluation of the SAM according to Enterprise Architecture Framework Requirements " in MOSIM 2014 10eme Conference Francophone de Modelisation, Optimisation et Simulation, Nov 2014, Nancy France, Nov 2014.

[22] European Council, "Presidency conclusions-Lisbon European Council," European Council, vol. 100/1/00.

[23] Business Process Model and Notation (BPMN) v2.0.2, OMG, 2013. [Online]. Available: http://www.omg.org/spec/BPMN/2.0.2

[24] OMG UML version 2.5.1, OMG, 2017. [Online]. Available: http://www.omg.org/spec/UML/2.5.1 